COVID-19

\title{
Overview of different modified full-face snorkelling masks for intraoperative protection
}

\author{
Panoramica delle diverse maschere snorkelling modificate per la protezione \\ intraoperatoria
}

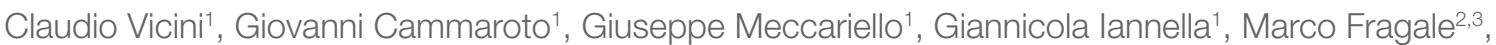
Tommaso Cacco 2,3, Claudio Sampieri2,3, Luca Guastini2,3, Eolo Castello ${ }^{2,3}$, Giampiero Parrinello ${ }^{2,3}$, Andrea De Vito4, Giampiero Gulotta ${ }^{5}$, Irene Claudia Visconti ${ }^{5}$, Pietro Abita ${ }^{6}$, Stefano Pelucchi ${ }^{7}$, Giulia Bianchi ${ }^{7}$, Michela Nicole Melegatti ${ }^{7}$, Gianluca Garulli ${ }^{8}$, Filippo Bosco ${ }^{9}$, Alessandro Gennaiotti ${ }^{9}$, Stefano Berrettini ${ }^{10}$, Massimo Magnani ${ }^{11}$, Marco Troncossi ${ }^{12}$, Giorgio Peretti2,3

${ }^{1}$ Department of Head-Neck Surgery, AUSL Romagna, Italy - Ear Nose Throat (ENT) Unit of Forli and Faenza, University of Ferrara and Bologna, Morgagni-Pierantoni Hospital, Forli, Italy; ${ }^{2}$ IRCCS Ospedale Policlinico San Martino, Unit of Otorhinolaryngology Head and Neck Surgery, Genoa, Italy; ${ }^{3}$ Department of Surgical Sciences and Integrated Diagnostics (DISC), University of Genoa, Italy; ${ }^{4}$ Department of Head-Neck Surgery AUSL Romagna, Italy - Ear Nose Throat (ENT) Unit, Santa Maria delle Croci Hospital, Ravenna, Italy; ${ }^{5}$ Department of Organ of Sense, University La Sapienza, Rome, Italy; ' Department of Adult and Development Age Human Pathology "Gaetano Barresi", Unit of Otorhinolaryngology, University of Messina, Italy; ${ }^{7}$ Otolaryngology Head and Neck Surgery, University Hospital of Ferrara, Italy; ${ }^{8}$ Minimally Invasive General and Thoracic Surgery Unit, AUSL Romagna, Italy - Ceccarini Hospital, Riccione, Italy; ${ }^{9}$ Department of Anesthesia and Intensive Care, Cisanello Hospital, University Hospital of Pisa, Italy; ${ }^{10}$ Otolaryngology Head and Neck Surgery, Cisanello Hospital, University Hospital of Pisa, Italy; ${ }^{11}$ Department of Head-Neck Surgery AUSL Romagna, Italy; Ear Nose Throat (ENT) Unit, Bufalini Hospital, Cesena, Italy; ${ }^{12}$ Department of Industrial Engineering, University of Bologna, Italy
\end{abstract}

\section{SUMMARY}

Objective. The COVID-19 pandemic has caused significant impact on healthcare systems worldwide. The rate of infected healthcare workers is $>10 \%$ in Italy. Within this dramatic scenario, the development of new personal protective equipment (PPE) devices is mandatory. This study focuses on validation of modified full-face snorkel masks (MFFSM) as safe and protective equipment against SARS-CoV-2 infection during diagnostic and therapeutic procedures on the upper aerodigestive tract.

Methods. Five different MFFSM were tested during otolaryngological surgery and in anaesthesia procedures. Data were collected through an online survey to assess the feedback of operators. $\mathrm{pO}_{2}$ and $\mathrm{pCO}_{2}$ monitoring values during procedures were recorded in selected cases. Results. All five MFFSM tested were easy to use and gave all operators a sound "feeling" of protection. All clinicians involved had common agreement regarding safety and the userfriendly format.

Conclusions. In the future, specific development of different type of masks for protection in the operating room, intensive care units and/or office will be possible as a joint venture between clinicians and developers. Goals for clinicians include better definition of needs and priorities, while developers can devote their expertise to produce devices that meet medical requirements.

KEY WORDS: COVID-19, pandemic, surgery, anesthesia

\section{RIASSUNTO}

Obiettivo. La pandemia di COVID-19 ha tuttora un impatto significativo sui sistemi sanitari di tutto il mondo. Il tasso di operatori sanitari italiani che hanno contratto l'infezione è superiore al 10\%. In questo drammatico scenario, la comunità scientifica si è impegnata nello sviluppo di nuovi dispositivi di protezione individuale. Il nostro studio si concentra sull'uso di maschere da snorkelling modificate (MFFSM) come dispositivi di protezione individuali contro l'infezione da virus COVID-19 durante procedure diagnostiche e terapeutiche sul tratto aerodigestivo superiore. Metodi. Cinque diversi tipi di MFFSM sono stati testati. I dati sono stati raccolti attraverso un sondaggio online; solo per la maschera OceanReef Aria QR+ sono stati registrati $i$ valori intraoperatori di $\mathrm{pO}_{2}$ e $\mathrm{pCO}_{2}$.

Risultati. Tutte le MFFSM testate si sono rivelate di facile utilizzo e tutti gli operatori hanno riferito una sensazione di comfort, mantenendo una sensazione di sicurezza durante la procedura.
Received: May 9, 2020

Accepted: May 23, 2020

Published online: September 24, 2020

\section{Correspondence}

Claudio Vicini

Via Carlo Forlanini 34, 47121 Forlì, Italy

E-mail: claudio@claudiovicini.com

Funding

None.

Conflict of interest

The Authors declare no conflict of interest.

How to cite this article: Vicini C, Cammaroto G, Meccariello G, et al. Overview of different modified full-face snorkelling masks for intraoperative protection. Acta Otorhinolaryngol Ital 2020;40:317324. https://doi.org/10.14639/0392-100X-N0841

(C) Società Italiana di Otorinolaringoiatria e Chirurgia Cervico-Facciale

\section{(c) (1) $(2)$}

This is an open access article distributed in accordance with the CC-BY-NC-ND (Creative Commons Attribution-NonCommercial-NoDerivatives 4.0 International) license. The article can be used by giving appropriate credit and mentioning the license, but only for non-commercial purposes and only in the original version. For further information: https:// creativecommons.org/licenses/by-nc-nd/4.0/deed.en 
Conclusione. In futuro sarà possibile lo sviluppo di specifiche maschere per la protezione in sala operatoria e in terapia intensiva sulla base di una stretta collaborazione tra clinici e ingegneri. L'obiettivo per i medici sarà definire con precisione le loro esigenze, mentre per le industrie produttrici sarà mettere a disposizione il loro expertise per fornire dispositivi che incontrino le necessità sanitarie.

PAROLE CHIAVE: COVID-19, pandemia, dispositivi di protezione individuale, maschera, chirurgia, anestesia

\section{Introduction}

The COVID-19 pandemic has caused significant impact on healthcare systems worldwide and is perhaps the most demanding challenge of the last decades. Infected healthcare workers represent more than $10 \%$ of all COVID-19 cases in Italy, thus highlighting the relevant involvement of this professional category ${ }^{1}$. Unfortunately, there is limited knowledge about the biological behaviour, transmission and spread of the SARS-CoV-2 virus, and up to now only empirical treatments and preventive methods against infection have been employed ${ }^{2}$. Direct contact (direct/indirect touching) and virus-containing aerosolised droplets during cough, sneezing and speaking within few metres are believed to be the main routes of the spread of infection. However, the hypothesis that the virus is diffuse in air, as its predecessor SARS-CoV-1, is well supported ${ }^{3}$.

There is evidence that a relevant rate of droplets expired containing virus become much smaller after water evaporation reaching 5 microns of dimension without gravitation effects and are free to travel in the air even at considerable distances; experimental studies show that SARS-CoV-2 remains active in aerosols for at least 3 hours and on nonporous surfaces for up to 72 hours ${ }^{4-6}$.

These pathways of viral spread and its high stability in indoor environments can explain the high risk of disease transmission, causing a significant number of nosocomial infections and consequently a high risk of exposure to the virus for healthcare personnel. Several other reasons, such as insufficient training of medical and paramedical staff, limited and partially ineffective diagnostic testing and shortage of personal protective equipment (PPE) ${ }^{7}$ seem to be the main causes of the dramatic peaks of infections in hospitals.

In particular, shortage of "second level" PPE such as N95, FFP-2 and FFP-3 masks has led some authors to investigate the possibility of re-use following feasible sterilisation methods ${ }^{8}$.

Swennen et al. ${ }^{9}$ proposed a re-usable custom-made 3Dprinted face mask as a valid alternative in order to reduce the need for disposable PPEs.

Another recently explored solution is the use of 3D printed adaptors that support the matching of widely used standard anesthetic heat and moisture exchange (HME) or industrial FFP3 filters, to commercially available snorkelling masks ${ }^{10}$. Snorkelling masks were originally introduced in management of COVID-19 patients as an emergency interface for continuous positive airway pressure (CPAP). After that, diffusion of snorkelling masks as a protective tool for medical and paramedical staff occurred at a worldwide level.

The snorkelling mask is a single tool acting, at the same time, as a mouth/nose protection mask and as eye protection glasses. Moreover, the device is waterproof and capable of completely sealing the face of operators. The low price and wide availability of these masks make them a potentially rapid and feasible solution to provide PPE during the pandemic. Greig et al. ${ }^{11}$ were the first authors to publish a case report on safety testing of a snorkeling mask, which highlighted some interesting perspectives.

The standardisation of re-usable devices would lead to a significant reduction of costs and to a reduced need for disposable PPE. However, FDA or CE approval of such equipment is still needed, and research is expected to accelerate. The aim of our multicentre prospective study is to report on the use of different models of modified full-face snorkel masks (MFFSM) equipped with 3D printed adaptors for HME and FFP3 filters, evaluating several practical aspects such as safety and comfort from the perspectives of surgeons and anesthesiologists. Taking into account the demonstrated efficacy of HME and FFP3 filters, our study does not include a specific evaluation of the protective activity of MFFSM against infection. A brief discussion of the ethical and regulatory issues, with recommendations for the future, is also included.

\section{Materials and methods}

Tests of MFFSM devices were conducted from JanuaryApril 2020 in three tertiary referral centres: Otolaryngology Unit of the Morgagni-Pierantoni Hospital, Forlì, Italy, Intensive Care Unit (ICU), University of Pisa, Pisa, Italy, and Otolaryngology Unit and ICU of IRCCS Ospedale Policlinico San Martino, University of Genoa, Genoa, Italy.

Five different MFFSMs were tested during anaesthesiologic and head-neck surgical procedures in operating room (OR) and endoscopic evaluations in the ICU. The first and newest versions of Subea Easybreath (Decathlon, Villeneuved'Ascq, France), Seac Unica (Seac Sub, San Colombano Certenoli, Genova Italy), Siropack C-Voice, (Siropack, Cesenatico, Forlì - Cesena Italy), based on the Unica mask model, and the OceanReef Aria QR+ (Mestel Safety, Genoa, 
Italy) (Figs. 1A-E). Both the first and newest versions of Decathlon masks were modified by the addition of 3D printed adapters that support the possibility to connect the mask to standard anaesthesiologic filters (HME-FFP2 filter). In the same way, the OceanReef and Unica masks were equipped with a patented adapter coupled to a standard HME filter and industrial FFP3 (Figs. 2A-E).

The Siropack mask has an integrated upper filter and an internal microphone connected to an external amplification system that allows communication between the surgeon and/or the anaesthesiologist and the OR and ICU teams (Fig. 1D).

The equipment of the surgeon with all different MFFSM devices is shown in Figure 3. The use of MFFSM during different surgical procedures is shown in Figure 4. The Seac Unica mask was used only in diagnostic procedures in the ICU such as fibrolaryngoscopies and phoniatric evaluations.

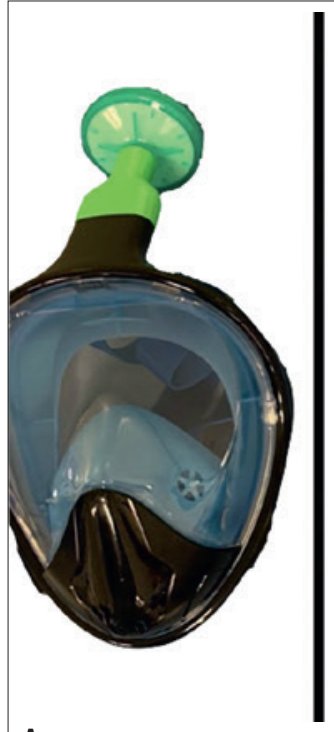

A

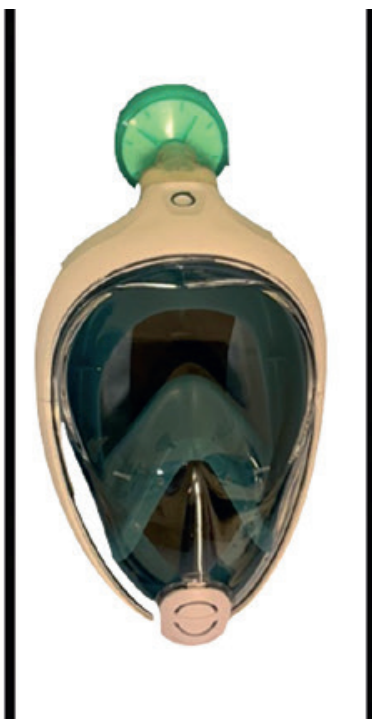

B

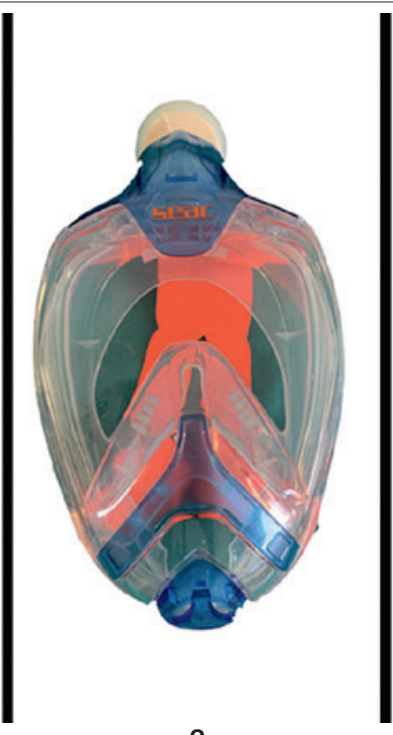

C

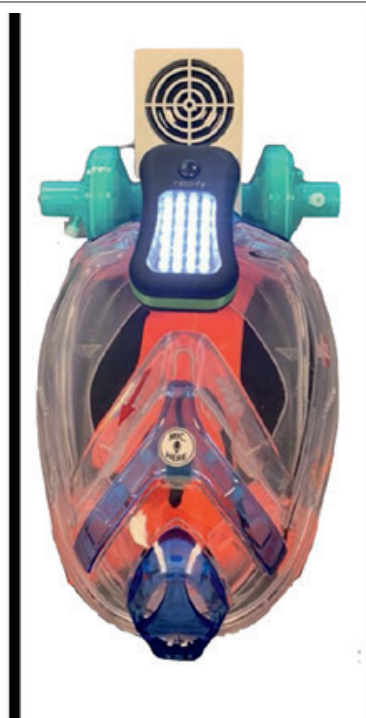

D

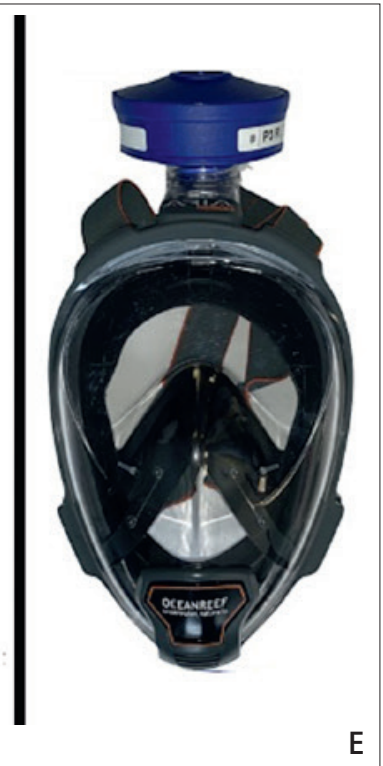

$\mathrm{E}$

Figure 1. (A,B) first and newest versions of Decathlon Subea Easybreath mask; (C) Seac Unica mask; (D) Siropack C-Voice mask; (E) Ocean Reef Aria QR+ mask.

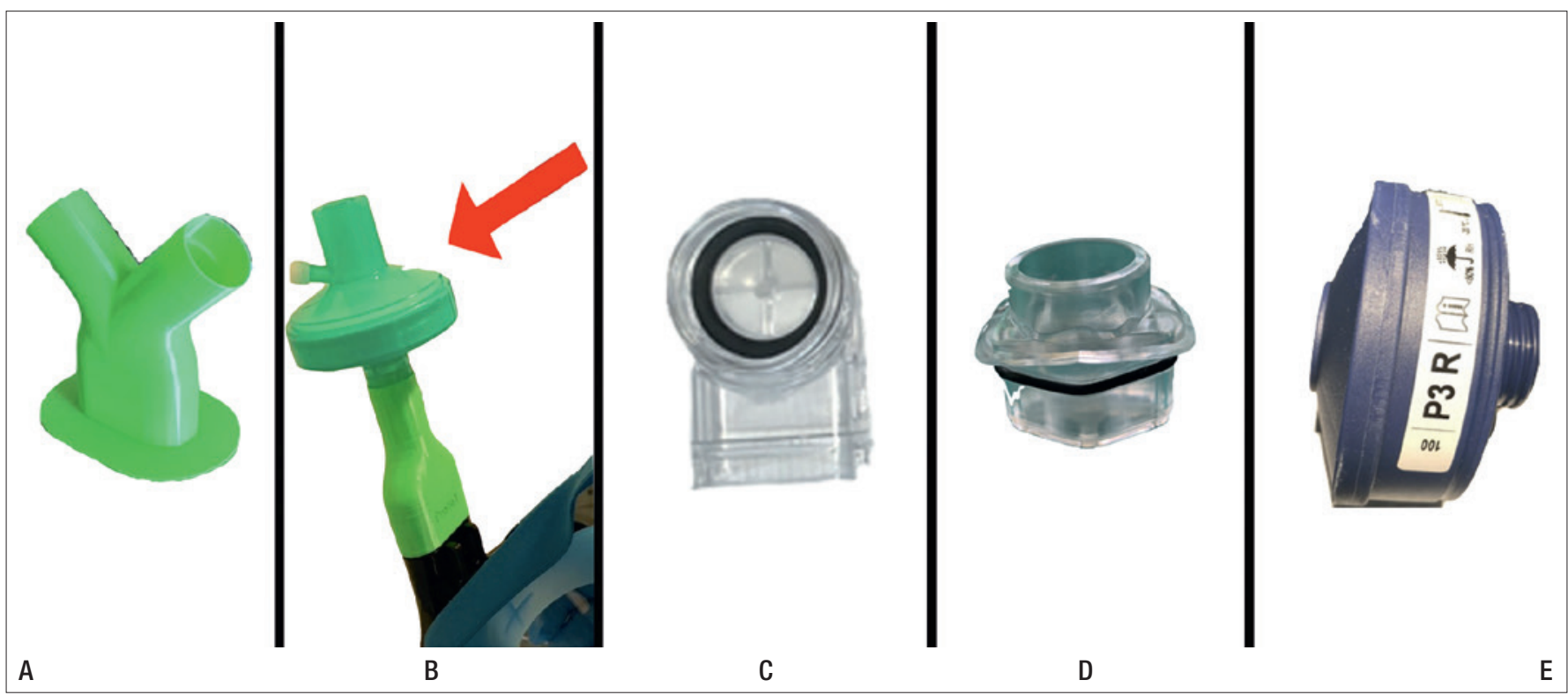

Figure 2. (A) 3D printed adapters for Decathlon Subea Easybreath; (B) Decathlon mask connected to standard anaesthesiologic filter (HME-FFP2 filter; arrow) with a 3D printed adapter; (C) adapter that allows connection of different industrial filters to the Ocean Reef Aria QR+ mask; (D) Seac Unica 3D printed adapter; (E) industrial FFP3 filters that can be used with the OceanReef Aria QR+ mask. 


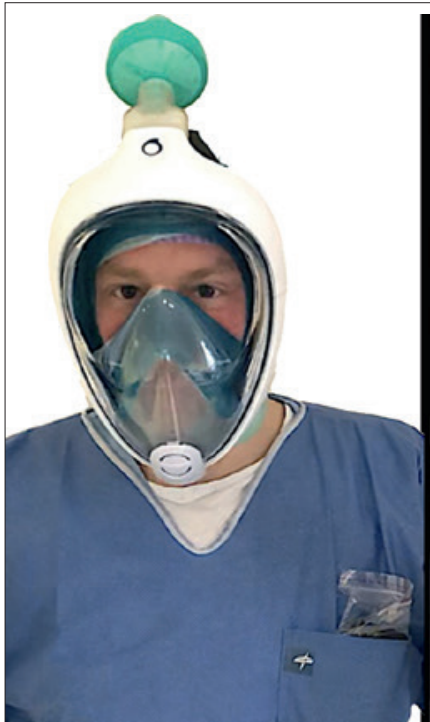

A

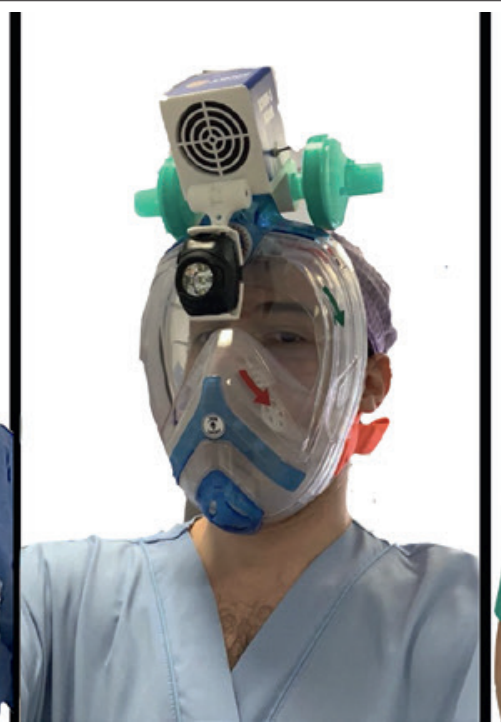

B

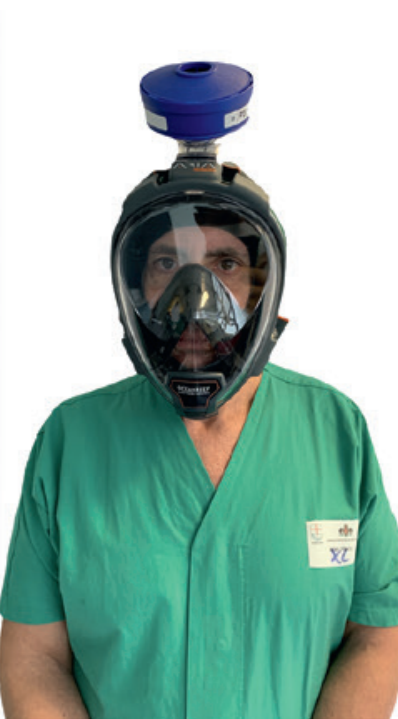

C

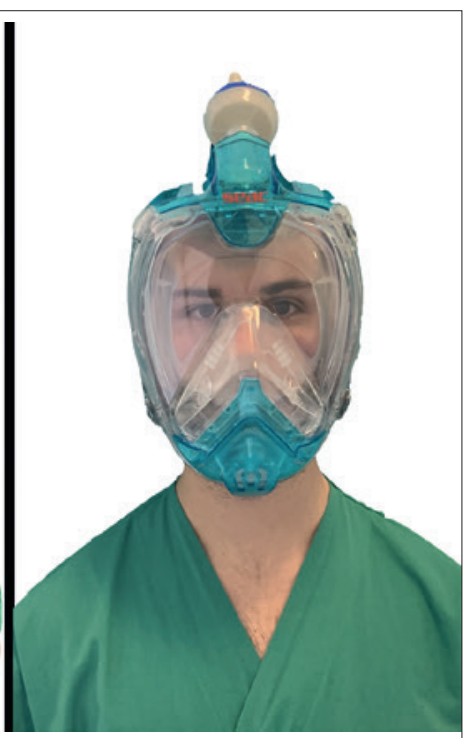

D

Figure 3. Surgeons wearing four different types of modified snorkelling masks; (A) modified Decathlon mask; (B) Siropack C-Voice mask; (C) Ocean Reef Aria QR+ mask; (D) Seac Unica mask.

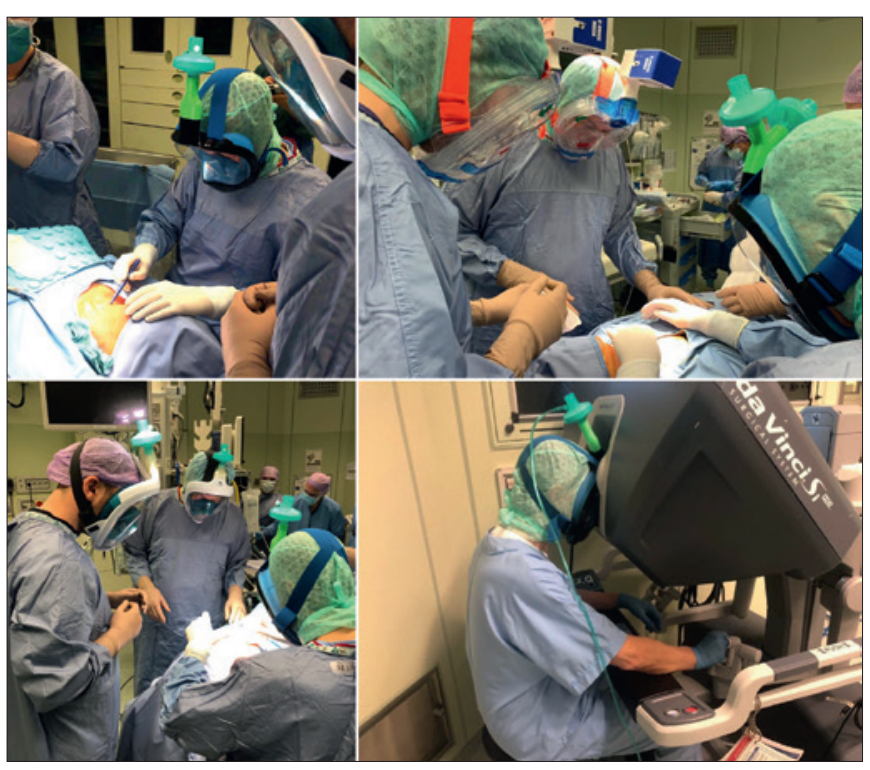

Figure 4. Arrangement of the surgical team, equipped with modified fullface snorkel masks, during different surgical procedures.

The subjective analysis for every model of MFFSM was based on an online survey to assess operators feedback about the mask during different types of anaesthesiologic or surgical procedures in the OR and ICU. The survey was created with Google Survey (Mountain View, California, USA), so that each participant could complete the survey only once.

The survey was developed in an interactive fashion, with drafts revised by four different authors. In the final version of the survey, there were multiple/single open-ended and closed-ended questions.
Information on difficulty in breathing, optical distortion, and perceived weight of each mask was collected in the survey using a Visual Analogue Scale (VAS). These parameters were evaluated with a VAS using a 1-10 numerical rating scale $(1=$ no impact; $10=$ high impact; intermediate values with increasing degrees of impact on tested items). Comfort and fitting, ease of use, and lateral and central vision quality were evaluated with a VAS using a 1-10 numerical rating scale $(1=$ high impact; $10=$ no impact; intermediate values with decreasing degrees of impact on tested items).

Communication between members of the surgical team, due to the sound attenuation caused by the mask, was assessed using a VAS with a $1-5$ score $(1=$ poor sound and lower verbal perception 1; $5=$ excellent sound and good verbal perception; intermediate values with increasing degrees of impact on tested item). The presence of water condensation that did not allow a clear vision of the surgical field was also investigated and scored as: none, disturbing, not disturbing. Finally, localised pressure or facial sores were considered as: none, slight evident, evident with painful.

Responses were anonymously collected. Incomplete responses were excluded from the analysis.

In addition, with OceanReef mask, $\mathrm{PO}_{2}$ and $\mathrm{PCO}_{2}$ values were objectively monitored during surgical procedures by positioning a probe on the lobe of the pinna of surgeons (SenTec V - Sign System, SenTec AG, Therwil, Basel, Switzerland). Cleaning and sterilisation of MFFSM was carried out immediately after each procedure following the institutional protocols adopted for goggles and protective visors, which took about 30 minutes to complete. 
Because there is no patient data, this study was exempt from the need for Institutional Review Board approval.

\section{Statistical analysis}

Descriptive statistical analysis was made by MannWhitney U test (SPSS version 22,0; IBM Corp, Armonk, NY, USA) to compare different items investigated in three MFFSM devices. Since it was not used for anaesthesiologic and surgical procedures, data for the Seac Unica mask was excluded from statistical analysis.

\section{Results}

\section{General results}

All procedures were performed in COVID-19 free patients, confirmed by preoperative polymerase chain reaction (PCR) test on nasal and oro-pharyngeal swabs. Modified Decathlon masks (with COVIDIEN ${ }^{\circledR}$ DAR HME filter) were tested in 25 surgical and anaesthesiologic procedures in the OR, Siropack in 15, and Ocean Reef in 10 , respectively; Seac Unica was used in only 56 diagnostic

Table IA. Type of modified full-face snorkelling masks and number of procedures performed in OR and ICU.

\begin{tabular}{lc} 
Number of all procedures & $\mathbf{N}=106$ \\
Modified Decathlon masks (HME filter) & $25(24 \%)$ \\
Siropack mask (HME filter) & $15(14 \%)$ \\
Ocean Reef Aria (P3 industrial filter) & $10(9 \%)$ \\
Seac Unica (HME filter) & $56(53 \%)$ \\
\hline
\end{tabular}

Table IB. Number and type of surgical and anesthesiologic procedures in OR.

\begin{tabular}{lc} 
Number of surgical and anesthesiologic procedures & $\mathbf{N}=\mathbf{5 0}$ \\
ENT surgery & $35(70 \%)$ \\
Anaesthesiologic procedures & $15(30 \%)$ \\
Role of surgeon/operator & \\
Intubation & $15(30 \%)$ \\
First surgeon & $19(38 \%)$ \\
Second surgeon & $7(14 \%)$ \\
Third surgeon & $9(18 \%)$ \\
Type of anaesthesia & \\
General anesthesia & $48(96 \%)$ \\
Local anaesthesia & $2(4 \%)$ \\
Type of procedures & \\
Tracheotomy & $19(38 \%)$ \\
Oro-tracheal intubation & $15(30 \%)$ \\
Hemi-thyroidectomy & $5(10 \%)$ \\
Parotidectomy & $5(10 \%)$ \\
Total thyroidectomy & $4(8 \%)$ \\
Neck dissection & $1(2 \%)$ \\
Transoral robotic surgery & $1(2 \%)$ \\
Mean time of surgical procedures (min) & \\
Standard deviation & 55.9 \\
Higher value & 45.5 \\
Lower value & 180 \\
Median & 5 \\
\hline Seac & 40 \\
\hline
\end{tabular}

${ }^{*}$ Seac mask was excluded from statistical analysis because it was not used in surgical procedures.
Table II. Operator feedback using modified full-face snorkel masks in surgical procedures.

\begin{tabular}{|c|c|c|}
\hline & Mean & Median \\
\hline Ease of wearing & $9.2 \pm 0.8$ & 9 \\
\hline Comfort and fitting & $8.6 \pm 1.5$ & 9 \\
\hline Central vision quality & $8.7 \pm 1.4$ & 9 \\
\hline Lateral vision quality & $6.7 \pm 2.1$ & 7 \\
\hline Optical distortion of the surgical field & $2.8 \pm 2.1$ & 2 \\
\hline Difficulty in breathing & $2.7 \pm 2.3$ & 2 \\
\hline Perceived weight of the mask & $3.8 \pm 2.7$ & 2 \\
\hline Communication with team during surgery* & $3.7 \pm 1$ & 4 \\
\hline Surgeon $\mathrm{pCO}_{2} \min ^{\star \star}$ & $32.7 \pm 0.5$ & \\
\hline Surgeon $\mathrm{pCO}_{2} \max ^{\star \star}$ & $37.1 \pm 0.5$ & \\
\hline Surgeon $\mathrm{p}_{2}$ mean $^{\star *}$ & $96.8 \pm 0.8$ & \\
\hline \multicolumn{3}{|l|}{ Localised pressure or facial sores } \\
\hline Not evident & 48 & $96 \%$ \\
\hline Slight evident & 2 & $4 \%$ \\
\hline Evident with painful & - & - \\
\hline
\end{tabular}

endoscopic evaluations in the ICU. The mean duration of surgical and anaesthesiologic procedures was 55.9 minutes (Tab. IA). Data about surgical procedures are shown in Table IB.

Operator feedback about the MFFSM during surgical procedures was presented in Table II and plotted in Figure 5. Ease of wearing, comfort and fitting, achieved a median score of 9 .

Central vision quality showed a median value of 9 , whereas the median score for lateral vision was 7. Despite the mean excellent outcomes, both Decathlon masks, especially the first model, caused optical distortion at the converging gaze and was given a low score.

The absence of condensation inside the mask was reported by $94 \%$ of operators. On the other hand, the presence of condensation drops inside the chin valve was reported by some operators using Decathlon masks, especially after prolonged use ( $>40$ minutes), but did not interfere with the procedures. Ninety-six percent of testers did not complain of localised pressure or facial sores after use of the mask.

Operator feedback by mask

Differences in parameters between all masks used in surgical settings are reported in Table IIIA.

The quality of communication with the teams through the mask showed a significant difference in terms of effectiveness between the Siropack vs Decathlon masks $(\mathrm{p}=0.04)$. By contrast, the Siropack model was felt to have a greater perceived weight compared to the others 


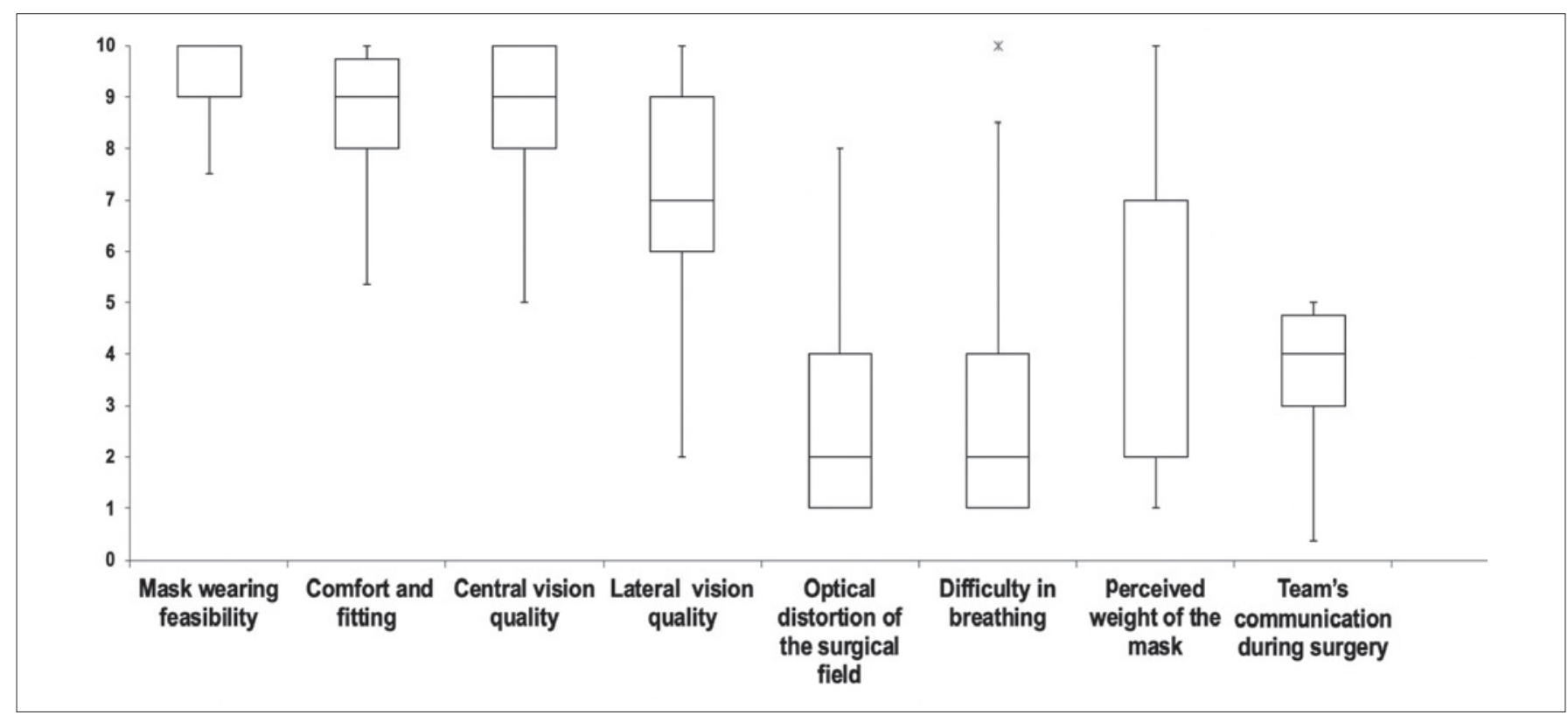

Figure 5. Box plot; operator feedback on the use of modified full-face snorkelling masks (Seac Unica excluded).

Table IIIA. Operator feedback: differences between modified Decathlon, Siropack, and Ocean Reef masks.

\begin{tabular}{|c|c|c|c|c|}
\hline & Modified Decathlon mask & Siropack mask & Ocean Reef mask & $\mathrm{p}$ \\
\hline Time of surgery & $48.0 \pm 55.8$ & $55 \pm 36.3$ & $53.5 \pm 18.7$ & $>0.05$ \\
\hline Ease of wearing & $9.4 \pm 1$ & $8.9 \pm 0.7$ & $9.5 \pm 0.5$ & $>0.05$ \\
\hline Comfort and fitting & $8.7 \pm 1.8$ & $8.1 \pm 0.7$ & $9.1 \pm 0.7$ & $>0.05$ \\
\hline Central vision quality & $8.8 \pm 1.7$ & $8.3 \pm 2.2$ & $9 \pm 0.8$ & $>0.05$ \\
\hline Lateral vision quality & $7 \pm 2.8$ & $6.5 \pm 1$ & $6.8 \pm 0.7$ & $>0.05$ \\
\hline Optical distortion of the surgical field & $2.9 \pm 2.7$ & $2.4 \pm 1.1$ & $3.1 \pm 2.2$ & $>0.05$ \\
\hline Difficulty in breathing & $2.9 \pm 2.9$ & $2.7 \pm 2.3$ & $2.1 \pm 2.4$ & $>0.05$ \\
\hline Perceived weight of the mask & $2.9 \pm 2.4$ & $5.8 \pm 1.1$ & $1.8 \pm 0.5$ & 0.03 * \\
\hline Communication with team during surgery ${ }^{\star \star \star \star}$ & $3 \pm 0.9$ & $4.1 \pm 0.7$ & $3.8 \pm 0.7$ & $\begin{array}{l}0.04^{\text {** }} \\
0.3^{\text {*** }}\end{array}$ \\
\hline
\end{tabular}

* Siropack vs decathlon and Ocean Reef mask; ** Siropack vs decathlon; ** Siropack vs Ocean Reef mask; **** all items except "time of surgery" were scored with a numerical rating scales of VAS =0-10; "communication with team during surgery" was scored with a numerical rating scale of VAS =0-5; Table IIIB; Operator feedback using modified Seac Unica in ICU procedures.

$(\mathrm{p}=0.03)$ due to the integration of a microphone and external amplificatory system (Tab. IIIA).

On the other hand, concerning the remaining items, no significant differences were seen between Siropack and OceanReef masks.

During $\mathrm{pO}_{2} / \mathrm{pCO}_{2}$ monitoring with the Ocean Reef model, the mean value of $\mathrm{pO}_{2}$ was $96.8 \mathrm{mmHg}$ and the mean of the highest $\mathrm{pCO}_{2}$ values recorded was $37.1 \mathrm{~mm} \mathrm{H}_{2} \mathrm{O}$, which was within the normal range $\left(\mathrm{p}<40 \mathrm{~mm} \mathrm{H}_{2} \mathrm{O}\right)$.

Notably, ICU operators performed more than one procedure without removing the mask. Each procedure took a mean time of 25 minutes, while the mean total wearing time was 4 hours. Condensation was reported only by operators wearing the mask for more than 4 hours, which did not, however, interfere with the procedures.
Central vision quality with the Seac Unica mask showed a mean value of 9.1 , lateral vision quality of 9 and optical distortion of 8 (Tab. IIIB).

Table IIIB. Operator feedback using modified Seac Unica in ICU procedures.

\begin{tabular}{lcc} 
& Average value & Median \\
Ease of wearing & $8.2 \pm 2.3$ & $\mathbf{9}$ \\
Comfort and fitting & $9.1 \pm 1.4$ & $\mathbf{9}$ \\
Central vision quality & $9.1 \pm 1.2$ & 9 \\
Lateral vision quality & $9.0 \pm 1.6$ & 9 \\
Optical distortion & $2.0 \pm 2.0$ & 1 \\
Difficulty in breathing & $2.6 \pm 2.0$ & 2 \\
Perceived weight of the mask & $3.5 \pm 2.4$ & 3 \\
Communication with team & $4.2 \pm 1$ & 4 \\
\hline
\end{tabular}

* all items were scored with a numerical rating scales of VAS $=0-10$; "communication with team" was scored with a numerical rating scale of VAS $=0-5$. 


\section{Discussion}

The COVID-19 pandemic, worldwide, was characterised in its first phase by a shortage of PPE, especially high-performance filtering masks FFP2 and FFP3 for healthcare workers (HCW). For this reason, industrial PPE devices (mask, filters, goggles) are tested and commonly employed for COVID-19 patients in hospitals and more generally in healthcare systems.

It is also extremely important to underline that all HCW performing trans-nasal and trans-oral endoscopic examinations (i.e. pharyngo-laryngoscopy, bronchoscopy, etc.) are exposed to the highest risk of infection ${ }^{6}$. Therefore, an adequate prevention of risk should be adopted, starting from the assumption that all patients are potentially infected with SARS-CoV-2 until proven otherwise.

For these reasons, the scientific community has punctually reported detailed international protocols and recommendations to minimise the risk of viral diffusion and infection, including the observance of specific surgical and anaesthesiologic procedures, new surgical team settings and constant use of adequate PPE ${ }^{12,13}$.

In this dramatic scenario, the development of new PPE devices is mandatory to guarantee all HCW the safest level of protection and comfort. Our study focused on the validation of MFFSMs as safe and protective equipment against SARS$\mathrm{CoV}-2$ infection, testing and both judging subjectively and objectively the efficacy and usability of these personal and customised devices during diagnostic and therapeutic procedures on the upper aerodigestive tract.

All tests were performed in patients who were confirmed to be SARS-CoV-2 negative. The aim of the study was to test the feasibility of the masks before using them on COVID-19 positive cases.

All the masks tested are currently available on the market, and significant differences in the quality among the devices were not seen.

All MFFSMs tested were easy to use and gave all operators a sound "feeling" of protection. It is also worth mentioning that the average score of the item related to the ease of wearing showed a median value of 9 .

The actual viral filtration capability was not tested and was not the goal of the present study. However, the filtering power of the system is based on the anaesthesiologic and professional filters, which are certified and widely used for a long time. The immediate possibility to combine commercial snorkelling masks with dedicated filters renders MFFSMs a safety emergency tool than can be successfully and immediately employed.

The values of $\mathrm{pCO}_{2}$ were tested only for the OceanReef mask, which were always within normal ranges throughout the procedure, objectively showing the stability of respiratory parameters that indicate correct breathing and normal air circulation in the mask. However, due to the similar structure of all devices analysed, this objective parameter is likely to be similar to the other masks as well.

However, comparison between MFFSMs and other conventional protective devices must be carefully taken into account. FFP2-3 masks, for instance, loose their filtering efficacy if they wet due to fluid penetration in the fabric; therefore, in case of incomplete face sealing, viral inhalation could not be excluded. Moreover, the need for FFP2-3 masks to be disposable increases both costs and problems related to their disposal.

Surgical goggles usually limit the vision inferiorly and laterally, often become foggy and cause significant discomfort. Face shields can be cumbersome, without adequate ventilation.

On the basis of our experience, the utilisation of a single full-face protection device such as a MFFSM instead of a combination of a FFP2 mask and goggles seems to be more user-friendly. Moreover, the respiratory fit test of the MFFSMs seems to be much more reliable than the respirator fit test of a conventional FFP2 mask.

The wide range of responses for items related to the comfort may reflect the less well-defined concept of "comfort" and individual sensitivity to a claustrophobic feeling induced by prolonged use of the device, but no significant differences were seen among the different models.

The optical properties of the masks may play a key role in their effective use in a surgical setting. Central vision was described as sufficient by most operators, but the masks were rated as critical in terms of lateral view, which is much less important during intubation manoeuvers. Different amounts of optical distortion were described for all the MFFSMs, such as barrel, pincushion, and mustache, which is related to the different shapes of the transparent shield of the masks. However, the optical distortion value was rated as non-critical for all masks. Some breathing difficulty was reported by operators using all types of MFFSM, which is probably related to the strength of air flow of the respiratory system which is plugged by a filtering membrane. The moderate increase in dyspnoea was mainly related to individual sensitivity and use of a double filter vs a single filter.

Furthermore, all MFFSM originally designed for snorkelling did not allow the use of loupes or even normal glasses. In light of this, an integrated magnification system and lighting would be useful, especially for specialists facing with diseases of the upper airways. This issue could be overcome by customised development of a new mask that is specific for clinical and surgical needs.

Another critical issue of extreme importance to be considered in future is to decrease, as much as possible, the weight of the device, even with the integration of different accessories, to avoid discomfort and neck fatigue. 
All MFFSM evaluated are immediately available and may be considered to be a practical emergency solution for personal protection in the operating room and ICU for Head and Neck and Anaesthesiologist teams during the COVID-19 pandemic. MFFSMs could play a key role in the emergency when conventional PPE (FPP2 or FPP3, transparent shields or goggles) is not immediately available or are in shortage. All the teams included in the study considered MFFMs to be a valid and interesting alternative option, even in the case that conventional PPE is available.

All models provided a waterproof barrier for the eyes, nose and mouth, which means for the entire face. The internal sealed respiratory space is filtered by certified devices, giving the user a reasonable level of biological safety, awaiting official certification. Breathing in the mask seems to be perceived in a different way by different surgeons, and sometimes with some degree of discomfort. The visualisation of the surgical field with MFFMs could allow the surgeon to perform regular activities in wide variety of surgical and anaesthesiologic situations, including selected lengthy and demanding surgeries. Illumination and voice communication system were only available in one MFFSM, which are recommended in the future. Nevertheless, a heavier MFFSM is the price to pay to include a double filter option and an integrated system of illumination and communication.

\section{Conclusions}

In addition to the required certifications, which will take a reasonably long time for official approval by different authorities, all the clinicians had common agreement for strongly recommended improvements:

1. a more customised mask for medical and surgical needs;

2. a fundamental requisite should be the possibility to use personal glasses inside the mask;

3. a miniaturised microphone/loudspeaker system is recommended for all medical activities;

4. for special activities (ENT, oral surgeons, plastic surgery, etc.), an integrated head lamp and possibly a magnifying loupe system would be valuable.

In the future, continuous cooperation and close interaction between clinicians and engineers will offer more performing devices for different branches of the healthcare system. Clinicians will be able to better define their needs and priorities, while manufacturers will focus on production of devices that meet all medical requirements.

\section{Acknowledgements}

Thanks to Mr. Salvatore Tabone, Dr. Marco Brancaleoni, Dr. Filippo Bosco e Mr. Calogero Sorce, and engineer Lorenzo
Zanchini a group of very talented and enthusiastic dreamers. A special mention for Siropack owners Rocco De Lucia e Barbara Burioli. They provided for free most of the masks included in the study. A special thanks to Eng. Gamberini, manager of the Ocean Reef Company, a leader for individual protection systems and to Dr. Princi, Project manager for their support for this project. We would like to express our sincere gratitude to Mr. Arata Daniele, President of Seac-Group for supporting our research, providing us novel and valuable insights for clinical practice. We are also grateful to Istituto Italiano di Tecnologia (IIT) staff in the figures of engineer Michele Gesino (Senior Technician) and engineer PhD Luca Fiorio (Chief Technician).

\section{References}

1 Istituto Superiore di Sanità. Epicentro. Sorveglianza integrata COVID-19 in Italia. https://www.epicentro.iss.it/coronavirus/sars-cov-2-sorveglianzadati [published 17 April 2020 - accessed April 17, 2020].

2 Morawska L, Cao J. Airborne transmission of SARS-CoV-2: the world should face the reality. Environ Int 2020;139:105730. https:// doi.org/10.1016/j.envint.2020.105730

3 Fineberg HV. Rapid expert consultation on the possibility of bioaerosol spread of the SARS CoV-2 for the COVID-19 pandemic (April 2020) In: The national Academic Press NRC. Washington DC: The national Academic Press National Research Council; 2020.

4 Meselson M. Droplets and aerosols in the transmission of SARSCoV-2. N Engl J Med 2020;382:2063. https://doi.org/10.1056/NEJMc2009324

5 van Doremalen N, Bushmaker T, Morris DH, et al. Aerosol and surface stability of SARS-CoV-2 as compared with SARS-CoV-1. N Engl J Med 2020;382:1564-7. https://doi.org/10.1056/NEJMc2004973

6 Meccariello G, Gallo O. What ENT doctors should know about COVID-19 contagion risks. Head Neck 2020;42:1248-9. https://doi. org/10.1002/hed.26190

7 Ranney ML, Griffeth V, Jha AK. Critical supply shortages - the need for ventilators and personal protective equipment during the COVID-19 pandemic. N Engl J Med 2020;382:e41. https://doi. org/10.1056/NEJMp2006141

8 van Straten B, de Man P, van den Dobbelsteen J, et al. Sterilization of disposable face masks by means of standardized dry and steam sterilization processes; an alternative in the fight against mask shortages due to COVID-19. J Hosp Infect 2020;20:30176-6. https://doi. org/10.1016/j.jhin.2020.04.001

9 Swennen GRJ, Pottel L, Haers PE. Custom-made 3D-printed face masks in case of pandemic crisis situations with a lack of commercially available FFP2/3 masks. Int J Oral Maxillofac Surg 2020;49:673-7. https://doi.org/10.1016/j.ijom.2020.03.015

10 Liu DCY, Koo TH, Wong JKK, et al. Adapting reusable elastomeric respirators to utilise anaesthesia circuit filters using a 3D-printed adaptor; a potential alternative to address N95 shortages during the COVID-19 pandemic. Anaesthesia 2020;75:1022-7. https://doi.org/10.1111/anae.15108

11 Greig PR, Carvalho C, El-Boghdadly K, et al. Safety testing improvised COVID-19 personal protective equipment based on a modified full-face snorkel mask. Anaesthesia 2020;75:970-1. https://doi. org/10.1111/anae. 15085

12 European Centre for Disease Prevention and Control. https://www. ecdc.europa.eu/en/covid-19-pandemic

13 Società italiana di Otorinolaringologia e Chirurgia-Cervico Facciale. https://www.sioechcf.it/news-covid-19 